\title{
Assessment of Infraorbital Nerve Parasthesia after ZMC Fracture and Its Surgical Repair
}

Samy Saeed El Naas Farag Allah*, Mahmoud Ahmad Abdallah, Wael Abd Almagid Almohandis, Bahaa Eldin Abdrabo Tawfik

Department of Oral and Maxillofacial Surgery - Faculty of Dental Medicine, Al-Azhar University, Cairo

* Corresponding author: Samy Saeed El Naas Farag Allah,

Mobile: (+20)1069007128, E-mail: samy.saeed.edu@gmail.com

\begin{abstract}
Background: Infraorbital nerve parasthesia is a very common finding after maxillofacial trauma involving zygomaticomaxillary complex (ZMC) region. The use of computer assisted surgical protocols for managing these fractures could improve the surgical outcome and maximize the functional and esthetic reconstruction of traumatized bones with possible effect on infraorbital nerve recovery.

Objective: The aim of the present study was to assess infraorbital nerve parasthesia after ZMC fracture and its surgical repair.

Patients and Methods: A total of 10 patients with unilateral ZMC fractures were selected from those having maxillofacial injuries at the Emergency Room of Sayed Galal University Hospital, Al-Azhar University, Cairo. Patients were divided randomly into two groups (five patients each); Group I: patients were treated with mirror imaging technique and fabrication of a steriolithographic (STL) model. Group II: patients were treated through the traditional technique without fabrication of an STL model.

Results: Infraorbital nerve affection occurred in 7 patients (70\%), 4 in group I and 3 in group II. Recovery of the nerve occurred at 3 months postoperatively except for only one patient from group II. Statistically, no significant difference was found between both groups.

Conclusion: Although computer assisted surgery is impressive and has a remarkable role in facilitating the precise contouring and adaptation of the titanium plates / mesh needed for fracture repair, it has no evident advantages over the traditional techniques regarding infraorbital nerve recovery.
\end{abstract}

Keywords: Zygomaticomaxillary complex fracture, infraorbital nerve, computer aided surgery.

\section{INTRODUCTION}

The zygomaticomaxillary (ZMC) complex is a quadripod composed of the lateral and inferior orbital rims, the zygomatic arch and the zygomaticomaxillary buttress. Several buttresses are incorporated in the ZMC: the zygomaticomaxillary buttress, the zygomaticotemporal buttress and the zygomaticofrontal buttress. These are points of articulation between facial bones that are common sites of fracture. These articulation points, or sutures, are inherently weak, resulting in an increased likelihood of fracture at these sites ${ }^{(\mathbf{1})}$.

The zygomatic bone forms the orbital floor and the lateral orbital wall and has two points where it contacts the maxilla and the cranium. Fractures of the body of the zygomatic bone are extremely rare and are usually caused by gunshot wounds. As for peacetime traumas, the term zygomatic bone fracture usually applies to trauma when the bone has been fractured at the sutures connecting the zygoma to the maxilla and cranium. Because of the complex anatomy and sutures of the zygoma, the pattern of fractures involving this bone is rather diverse ${ }^{(2)}$.

Fractures of the ZMC rank third in incidence among all bone injuries occurring in humans. The share of zygomaticoorbital fractures in children and adolescents is $60 \%$ of all facial fractures; in adults, this figure is $24-33 \%$, with only mandibular fractures being more frequent (70 $\%)^{(3,4)}$. In $40 \%$ of cases, the fractures affecting the zygomatic bone are accompanied by injuries to the maxilla, orbit, and nose as well as limb traumas ${ }^{(5)}$.

Acute loss of sensory function of the infraorbital nerve following ZMC fractures is often seen because of their close proximity as the nerve passes through the infraorbital sulcus in the floor of the orbit to exit through the infraorbital foramen. Traumatic injury to the infraorbital nerve may be due to compression, edema, ischemia, or laceration (6). The incidence of this complication in the longterm period varies from 15 to $50 \%$. Such a significant variance largely depends on study design and different patient selection criteria. Long-term persistence of neuropathy is determined both by the features of the fracture and the approaches used to manage it. Single-stage comprehensive surgical treatment involving open repositioning and rigid fixation of fragments with titanium plates plays a crucial role ${ }^{(7-10)}$.

However, even successful repositioning of the zygomatic bone is accompanied by dysesthesia in two-thirds of patients which may last up to 6 months. Temporary dysfunction of the infraorbital nerve was observed in $100 \%$ of cases after singlestage orbital floor reconstruction. There was no long-term difference in infraorbital nerve neuropathy occurring in patients with a minimally dislocated zygomatic bone whether or not they 
underwent open repositioning and rigid fixation of the zygomatic bone. The degree of late neurological disorders in patients subjected to single-stage orbital floor reconstruction holds an intermediate position between the groups of patients subjected to closed and open zygomatic bone repositioning ${ }^{(11-13)}$.

Technological advancements in imaging and surgical computer planning may assist the surgeon in this task (14-17). One of the most promising emerging technologies is the ability to use computer planning software to create a mirror image overlay (MIO) on a craniofacial computed tomographic CT scan. This involves duplicating the contralateral, non-traumatized, facial region and superimposing its skeleton onto the fractured, displaced region ${ }^{(\mathbf{1 8}, 19)}$. The use of mirror-imaging techniques with the aid of three dimensional computed tomographic (3DCT) scanning and 3D printing for reconstruction of orbital fractures could improve the outcome and maximize the functional and esthetic reconstruction of traumatized orbit ${ }^{(\mathbf{2 0}, \mathbf{2 1})}$.

This study has assessed infraorbital nerve parasthesia associated with ZMC fractures before and after repair through two different techniques.

\section{PATIENTS AND METHODS}

A total of 10 patients with unilateral zygomaticomaxillary complex fractures were selected from those having maxillofacial injuries at the Emergency Room of Sayed Galal University Hospital, Al-Azhar University, Cairo. Patients were divided randomly into two groups (five patients each); Group I: patients were treated with mirror imaging technique and fabrication of a rapid prototype skull model. Group II: patients were treated through the traditional technique without fabrication of a rapid prototype skull model.

\section{Ethical considerations:}

All patients were informed about the scope of the study and signed an informed written consent form.

\section{Ethical approval:}

An approval of the study was obtained from Al- Azhar University academic and ethical committee. Every patient signed an informed written consent for acceptance of the operation.

\section{Preoperative evaluation and preparation: Clinical examination:}

Clinical examination, including general, local and ophthalmological examinations, was done. An ophthalmologist was consulted to assess the visual acuity, diplopia and perform forced duction test (FDT) if the gaze was found to be restricted. Patients were evaluated clinically for the following: skin wounds, periorbital hematoma and infraorbital nerve affection (Figure 1).

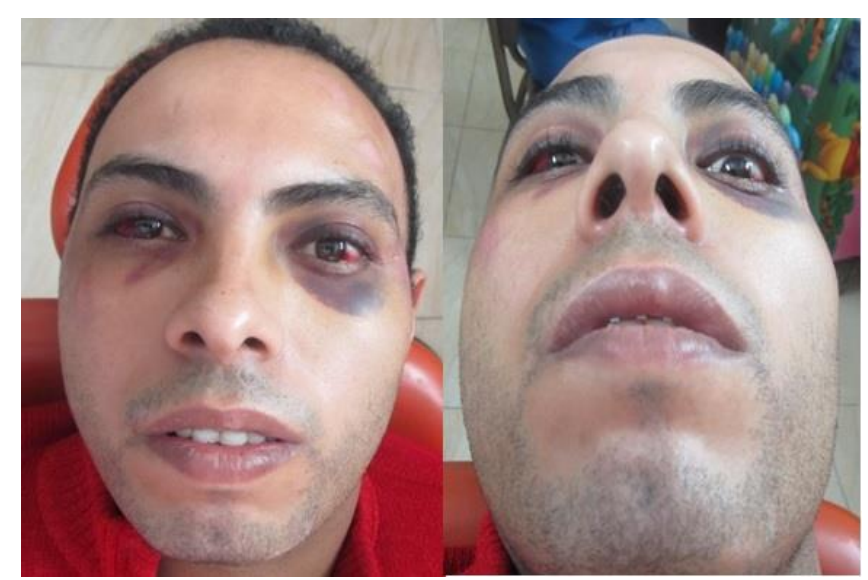

Figure (1): Preoperative clinical examination of the traumatized patient showing facial asymmetry and periorbital hematoma

\section{Radiographic examination:}

CT scanning of the skull was performed to assess the following:

- Location, direction and complications of the fracture.

- Design and manufacture a rapid prototype skull model of the mirror imaged unaffected side.

\section{III: Preparation of STL model:}

With the aid of the 3DCT scan of the skull, rapid prototype skull model was manufactured. Scanned DICOM (Digital Imaging and Communications in Medicine) images were imported to Mimics software (Materialise, Leuven, Belgium). The normal uninjured side of the orbital $\mathrm{ZMC}$ region was reflected onto the contralateral injured side.

The mirror imaged STL model data were used to manufacture a rapid prototype skull model by $3 \mathrm{D}$ printing technique (Dent 1 DLP 3D printer using Funtodo resin). This life-size rapid prototype skull model which resembles the individual skull model of the uninjured side was used to precontour the titanium mesh and / or miniplate (s) which were used in the reconstruction of the ZMC. The precontoured plates / mesh were sterilized carefully so as not to distort the predetermined contouring. (Figure 2) 


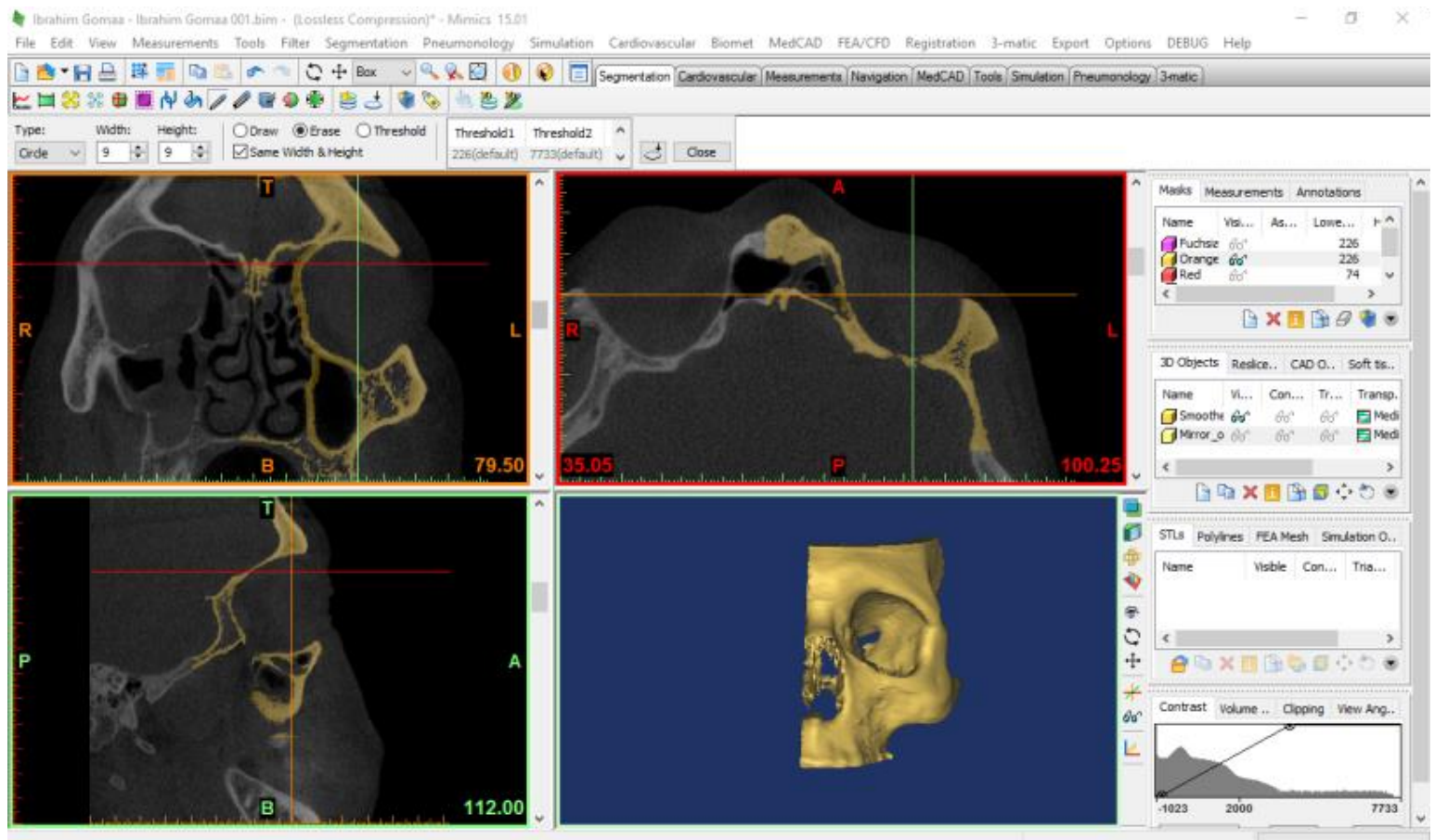

Figure (2): mirror imaging technology using Mimics software overlapping the unaffected side onto the fractured one ad an STL model was designed

\section{IV: Operative technique:}

After general anesthesia was established, the anesthetic tube was secured to the patients head and an antiseptic eye ointment was applied carefully to the palpebral fissures. The surgical field was scrubbed with antiseptic solution and the patient was draped with sterile towels secured by towel clips leaving only the surgical field uncovered. A temporary lid suspension suture was carried out in order to stabilize and retract the lower lid. Subciliary incision was made through the skin only and hemostasis was achieved. Dissection through the orbicularis oculi muscle was done in a stepped myocutaneous flap design. The periosteum over the inferior orbital rim was sharply incised down to bone and elevated using a periosteal elevator to expose the fracture line. The globe was retracted carefully to explore the integrity of the orbital floor. Entrapped soft tissue was repositioned back into the orbit. An additional lateral eye brow incision was utilized to expose the frontozygomatic suture.

An intraoral maxillary vestibular incision was performed to expose midface fractures and to permit mobilization and reduction of the fractured zygomaticomaxillary complex. The fractured bones were freely mobilized and reduced into normal position. In group I, the preformed titanium mesh or/and plates were used as a template to assess the reduction of bones. Then, the reduced segments were fixed using the titanium plates and screws. (Figure 3). In group II, the titanium mesh or/and plates were manually bent to adapt to the surface of reduced bone fragments then fixed by the same way as in group I.

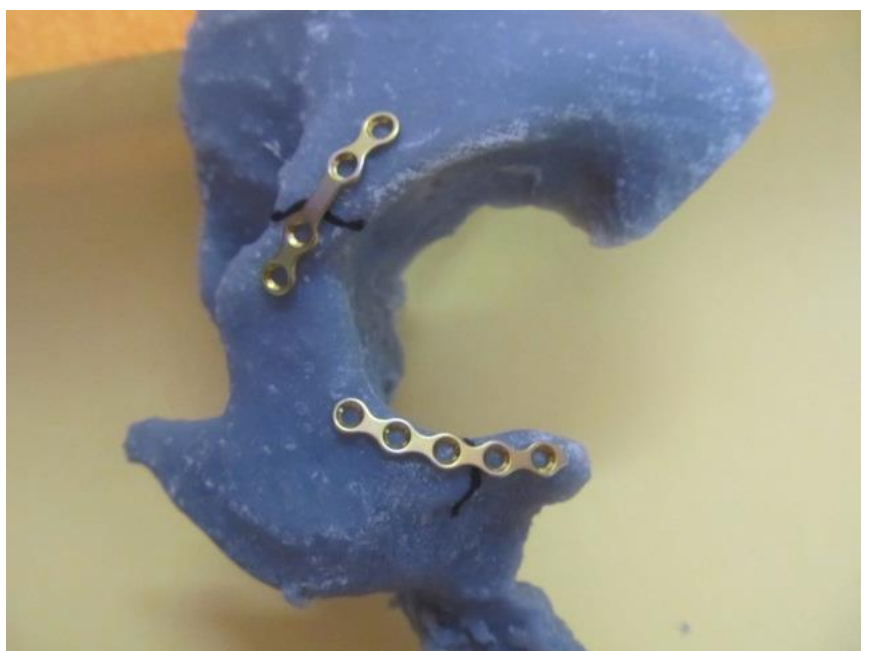

Figure (3): Preoperative contouring of the titanium miniplates on the 3D printed stereolithographic model

A drill pit rotating in a slow speed under copious saline irrigation was used to prepare bony osteotomies for the screws. The screws were inserted into bone through the plate holes and tightened carefully under saline irrigation with a suitable screw driver.

The surgical field was thoroughly irrigated with saline to remove debris. The wound was then closed in layers. Resorbable Vicryle 3-0 suture material was used to close the muscle layer and subcutaneous tissue with adequate simple interrupted stitches. The skin was closed using 5-0 Prolene suture material. The intraoral incision was 
closed with Vicryle 3-0 suture material with locking continuous suturing technique. The suspensory lower lid suture was suspended to the patient forehead for two days after surgery and the eye was covered with a sterile eye patch. Stitches were removed after one week.

\section{V: Postoperative assessment: \\ $>$ Clinical evaluation:}

Patients were evaluated clinically after one week, and at one, three and six months postoperatively for the following: wound site healing (infection and or dehiscence), infraorbital nerve parasthesia, periorbital hematoma and gaze restriction.

\section{$>$ Radiographic evaluation:}

Postoperative CT scanning was performed immediately after surgery and 6 months postoperatively to evaluate the final outcome of the reduced bones and position of the implant material.

\section{VI: Statistical analysis of the data}

Data were fed to the computer and analyzed using IBM SPSS software package version 20.0. (Armonk, NY: IBM Corp). Qualitative data were described using number and percent. The Kolmogorov-Smirnov test was used to verify the normality of distribution. Quantitative data were described using range (minimum and maximum), mean, standard deviation and median. Significance of the obtained results was judged at the $5 \%$ level.

\section{RESULTS}

Ten male patients were included in the study after thorough clinical and radiographic examination confirming their eligibility criteria of selection. All of them have committed for every recall during the whole follow up observation period. They were divided randomly into two groups; five patients each. All cases of both groups showed an uneventful healing of their soft tissue and bony wounds without any infection, dehiscence nor plate exposure after completion of surgery. All fractured bones within both groups were favorably reduced and fixed.

\section{Periorbital hematoma:}

In group I, all patients (5) were presented with periorbital hematoma. After one week only one patient resolved from the hematoma. This was statistically insignificant. After 1, 3 and 6 months, complete resolution of the periorbital hematoma occurred in all patients. The difference was statistically significant. In group II, 4 patients were presented with periorbital hematoma. After one week no patients were resolved from the hematoma. This was statistically insignificant. After 1, 3, and 6 months, complete resolution of the periorbital hematoma occurred in all patients. The difference was statistically significant. A statistically insignificant difference between both groups in periorbital hematoma was observed preoperatively and at either postoperative interval period. (Tables 1,2 )

Table (1): Changes in periorbital hematoma along the different observation periods within groups

\begin{tabular}{|c|c|c|c|c|c|c|c|c|c|c|c|}
\hline & \multicolumn{10}{|c|}{ Periorbital hematoma } & \multirow{4}{*}{$\mathbf{p}_{1}$} \\
\hline & \multirow{2}{*}{\multicolumn{2}{|c|}{$\begin{array}{c}\text { Pre- } \\
\text { operative }\end{array}$}} & \multicolumn{8}{|c|}{ Post-operative } & \\
\hline & & & \multicolumn{2}{|c|}{1 week } & \multicolumn{2}{|c|}{1 month } & \multicolumn{2}{|c|}{3 months } & \multicolumn{2}{|c|}{6 months } & \\
\hline & No. & $\%$ & No. & $\%$ & No. & $\%$ & No. & $\%$ & No. & $\%$ & \\
\hline Group I $(n=5)$ & & & & & & & & & & & \\
\hline Negative & 0 & 0.0 & 1 & 20.0 & 5 & 100.0 & 5 & 100.0 & 5 & 100.0 & $0001 *$ \\
\hline Positive & 5 & 100.0 & 4 & 80.0 & 0 & 0.0 & 0 & 0.0 & 0 & 0.0 & 0.001 \\
\hline $\mathbf{p}_{0}$ & & & \multicolumn{2}{|c|}{0.550} & \multicolumn{2}{|c|}{$0.003^{*}$} & \multicolumn{2}{|c|}{$0.003^{*}$} & \multicolumn{2}{|c|}{$0.003^{*}$} & \\
\hline Group II $(\mathbf{n}=5)$ & & & & & & & & & & & \\
\hline Negative & 1 & 20.0 & 1 & 20.0 & 5 & 100.0 & 5 & 100.0 & 5 & 100.0 & $0002 *$ \\
\hline Positive & 4 & 80.0 & 4 & 80.0 & 0 & 0.0 & 0 & 0.0 & 0 & 0.0 & 0.003 \\
\hline $\mathbf{p}_{0}$ & & & \multicolumn{2}{|c|}{1.000} & \multicolumn{2}{|c|}{$0.010^{*}$} & 0.0 & $10^{*}$ & \multicolumn{2}{|c|}{$0.010^{*}$} & \\
\hline
\end{tabular}

$\mathrm{p}_{1}: \mathrm{p}$ value for Cochran's test for comparing between the studied periods

$\mathrm{p}_{0}$ : $\mathrm{p}$ value for Post Hoc Test (Dunn's) for comparing between Pre-operative and each other periods

*: Statistically significant at $\mathrm{p} \leq 0.05$ 
Table (2): Changes in periorbital hematoma along the different observation periods between groups

\begin{tabular}{|c|c|c|c|c|c|c|c|}
\hline \multirow{2}{*}{\multicolumn{2}{|c|}{ Periorbital hematoma }} & \multicolumn{2}{|c|}{$\begin{array}{c}\begin{array}{c}\text { Group I } \\
(\mathbf{n}=5)\end{array} \\
\text { (n) }\end{array}$} & \multicolumn{2}{|c|}{$\begin{array}{c}\begin{array}{c}\text { Group II } \\
(\mathbf{n}=5)\end{array} \\
\end{array}$} & \multirow[t]{2}{*}{$\chi^{2}$} & \multirow[t]{2}{*}{${ }^{\mathrm{FE}} \mathbf{p}$} \\
\hline & & No. & $\%$ & No. & $\%$ & & \\
\hline \multicolumn{2}{|c|}{$\begin{array}{c}\text { Pre-operative } \\
\text { Negative } \\
\text { Positive }\end{array}$} & $\begin{array}{l}0 \\
5\end{array}$ & $\begin{array}{c}0.0 \\
100.0\end{array}$ & $\begin{array}{l}1 \\
4\end{array}$ & $\begin{array}{l}20.0 \\
80.0\end{array}$ & 1.111 & 1.000 \\
\hline \multirow{4}{*}{ 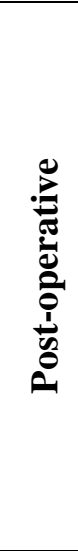 } & \begin{tabular}{|c|}
1 week \\
Negative \\
Positive \\
\end{tabular} & $\begin{array}{l}1 \\
4\end{array}$ & $\begin{array}{l}20.0 \\
80.0\end{array}$ & $\begin{array}{l}1 \\
4 \\
\end{array}$ & $\begin{array}{l}20.0 \\
80.0\end{array}$ & 0.000 & 1.000 \\
\hline & \begin{tabular}{|c|}
1 month \\
$\quad$ Negative \\
Positive \\
\end{tabular} & $\begin{array}{l}5 \\
0 \\
\end{array}$ & $\begin{array}{c}100.0 \\
0.0\end{array}$ & $\begin{array}{l}5 \\
0 \\
\end{array}$ & $\begin{array}{c}100.0 \\
0.0\end{array}$ & - & - \\
\hline & \begin{tabular}{|c|}
3 months \\
$\quad$ Negative \\
Positive \\
\end{tabular} & $\begin{array}{l}5 \\
0 \\
\end{array}$ & $\begin{array}{c}100.0 \\
0.0 \\
\end{array}$ & $\begin{array}{l}5 \\
0 \\
\end{array}$ & $\begin{array}{c}100.0 \\
0.0\end{array}$ & - & - \\
\hline & $\begin{array}{c}6 \text { months } \\
\text { Negative } \\
\text { Positive }\end{array}$ & $\begin{array}{l}5 \\
0\end{array}$ & $\begin{array}{c}100.0 \\
0.0\end{array}$ & $\begin{array}{l}5 \\
0\end{array}$ & $\begin{array}{c}100.0 \\
0.0\end{array}$ & - & - \\
\hline
\end{tabular}

$\chi^{2}$ : Chi square test

FE: Fisher Exact

$\mathrm{p}$ : $\mathrm{p}$ value for comparison between the two studied groups

\section{Infra orbital nerve affection:}

In group I, 4 patients were presented with paresthesia affecting the area supplied by their infraorbital nerve preoperatively and remained after one week. The difference was statistically insignificant. One month later, only one patient regained normal nerve function with no significant difference. After 3 , and 6 months, complete resolution of paresthesia occurred in all patients. The difference was statistically significant. In group II, 3 patients were presented with paresthesia affecting the area supplied by their infraorbital nerve preoperatively and remained at one week and one month observation periods. The difference was statistically insignificant. After 3 and 6 months, resolution of paresthesia occurred in only 2 patients. The difference was statistically insignificant. A statistically insignificant difference between both groups in infraorbital nerve affection was observed preoperatively and at either postoperative interval period. (Tables 3,4)

Table (3): Changes in infra orbital nerve affection along the different observation periods within groups

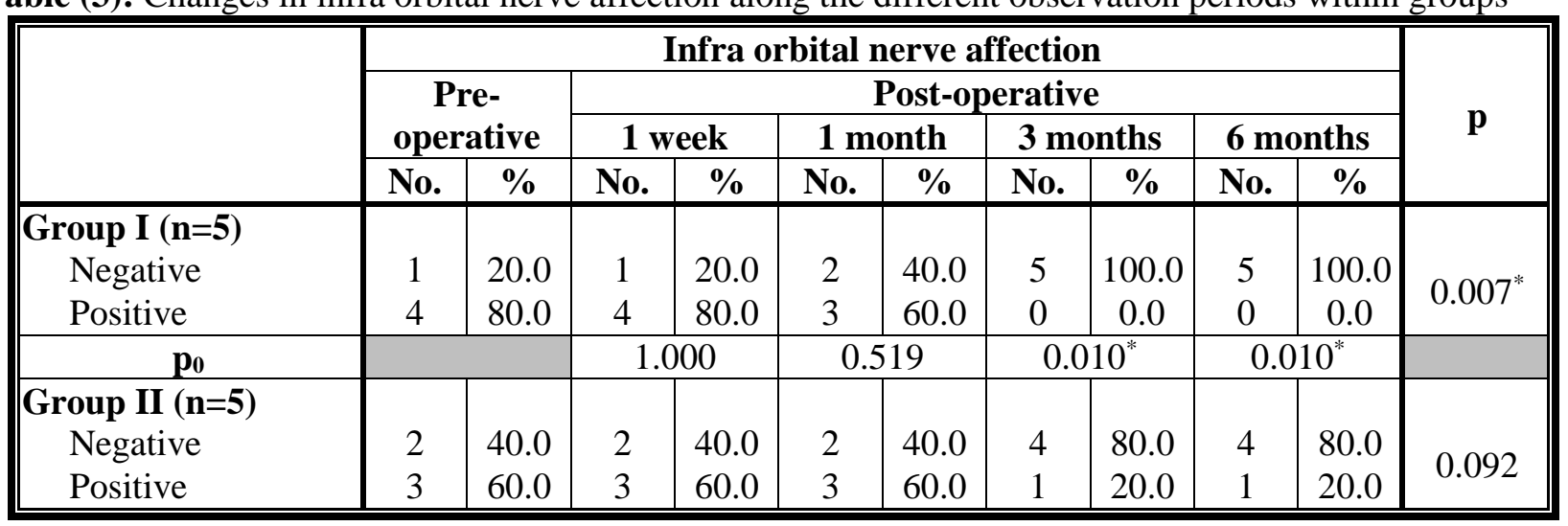

$\mathrm{p}_{1}: \mathrm{p}$ value for Cochran's test for comparing between the studied periods

$\mathrm{p}_{0}$ : $\mathrm{p}$ value for Post Hoc Test (Dunn's) for comparing between Pre-operative and each other periods

*: Statistically significant at $\mathrm{p} \leq 0.05$

Table (4): Changes in infra orbital nerve affection along the different observation periods between groups 


\begin{tabular}{|c|c|c|c|c|c|c|c|}
\hline \multirow{2}{*}{\multicolumn{2}{|c|}{ Infra orbital nerve affection }} & \multicolumn{2}{|c|}{$\begin{array}{c}\text { Group I } \\
(\mathbf{n}=5)\end{array}$} & \multicolumn{2}{|c|}{$\begin{array}{c}\text { Group II } \\
(n=5)\end{array}$} & \multirow[t]{2}{*}{$\chi^{2}$} & \multirow[t]{2}{*}{${ }^{\mathrm{FE}} \mathbf{p}$} \\
\hline & & No. & $\%$ & No. & $\%$ & & \\
\hline \multicolumn{2}{|c|}{\begin{tabular}{|c|}
$\begin{array}{c}\text { Pre-operative } \\
\text { Negative } \\
\text { Positive }\end{array}$ \\
\end{tabular}} & $\begin{array}{l}1 \\
4 \\
\end{array}$ & $\begin{array}{l}20.0 \\
80.0\end{array}$ & $\begin{array}{l}2 \\
3 \\
\end{array}$ & $\begin{array}{l}40.0 \\
60.0 \\
\end{array}$ & 0.476 & 1.000 \\
\hline \multirow{4}{*}{ 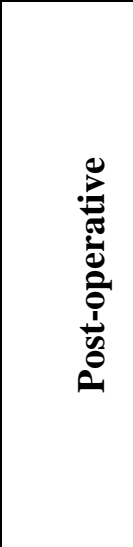 } & $\begin{array}{l}1 \text { week } \\
\quad \text { Negative } \\
\text { Positive }\end{array}$ & $\begin{array}{l}1 \\
4\end{array}$ & $\begin{array}{l}20.0 \\
80.0\end{array}$ & $\begin{array}{l}2 \\
3\end{array}$ & $\begin{array}{l}40.0 \\
60.0\end{array}$ & 0.476 & 1.000 \\
\hline & 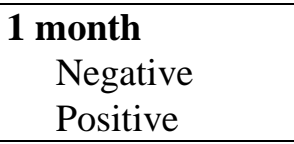 & $\begin{array}{l}2 \\
3 \\
\end{array}$ & $\begin{array}{l}40.0 \\
60.0 \\
\end{array}$ & $\begin{array}{l}2 \\
3 \\
\end{array}$ & $\begin{array}{l}40.0 \\
60.0 \\
\end{array}$ & 0.000 & 1.000 \\
\hline & $\begin{array}{l}3 \text { months } \\
\text { Negative } \\
\text { Positive }\end{array}$ & $\begin{array}{l}5 \\
0 \\
\end{array}$ & $\begin{array}{c}100.0 \\
0.0\end{array}$ & $\begin{array}{l}4 \\
1 \\
\end{array}$ & $\begin{array}{l}80.0 \\
20.0\end{array}$ & 1.111 & 1.000 \\
\hline & 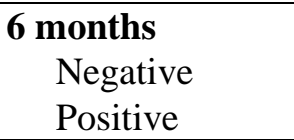 & $\begin{array}{l}5 \\
0\end{array}$ & $\begin{array}{c}100.0 \\
0.0\end{array}$ & $\begin{array}{l}4 \\
1\end{array}$ & $\begin{array}{l}80.0 \\
20.0\end{array}$ & 1.111 & 1.000 \\
\hline
\end{tabular}

$\chi^{2}$ : Chi square test FE: Fisher Exact

$\mathrm{p}$ : $\mathrm{p}$ value for comparison between the two studied groups

\section{DISCUSSION}

Ten patients with unilateral ZMC fractures were involved in the study. They were randomly divided into two groups. Group I in which the used titanium plates/mesh were previously contoured by adapting them on an STL model 3D printed of the mirror imaged unaffected side of the patient. While in Group II, the patients were managed through the traditional reduction and fixation techniques and the titanium plates/mesh were adapted intraoperatively to the reduced bony fragments.

Post-traumatic hematoma occurred in 9 patients ( 5 in group I and 4 in group II). It occurred due to extravasations or collections of blood into the subcutaneous tissues around the eyes. The fatty tissue along with the lack of muscle around the eye socket allows a potential space for blood accumulation. Post-traumatic or post-surgical collection of blood within the tissue planes" hematoma" is not considered an uncommon finding especially in traumatic injuries to the maxillofacial area, which is considered one of the highly vascularized organs of the human body. Within 10 days, the blood was gradually absorbed leaving an area of ecchymosis. The hematoma clearance may be via red blood cell lysis or phagocytosis. Erythrocytes within the clot preserve a normal biconcave configuration for a while and then start to lyse. At the same time, erythrocytes are phagocytized by microglia/macrophages ${ }^{(22)}$.

Findings of the present study revealed that the hematoma affecting the periorbital tissues preoperatively remained for one week in both groups. No patients were treated with evacuation of the hematoma. At 1, 3, and 6 months intervals, an uneventful total resolution of periorbital hematoma was evident in both groups. This is in accordance with Somasundaram et al. ${ }^{(23)}$ and Rajati et al. ${ }^{(24)}$. Somasundaram et al. ${ }^{(23)}$ found that the periorbital edema and ecchymosis can be associated with a variety of clinical features and most patients with periorbital edema and ecchymosis do not have injuries severe enough to require surgical intervention or post-discharge rehabilitation. Rajati et al. ${ }^{(24)}$ concluded that periorbital edema and ecchymosis are rare complications, which may be worrisome to the patients and their families, but they are self-limiting and essentially none dangerous conditions.

Orbital blowout fractures commonly occur along the floor of the orbit, medial to the infraorbital nerve canal. The infraorbital nerve within this canal is vulnerable to damage in many orbital floor fractures due to its proximity to the typical fracture site. Therefore, the infraorbital nerve may be contused, and the canal deformed, causing symptomatic paresthesia in the region of its distribution. In the current study, infraorbital nerve affection occurred in 7 patients (70\%), 4 in group I and 3 in group II. They were presented preoperatively with paresthesia affecting the middle portion of their faces supplied by the terminal branches of the infraorbital nerve. This is similar to the result of Sakavicius et al. ${ }^{(25)}$ who found that infraorbital nerve sensory disturbances were diagnosed in $64.4 \%$ of their patients.

Results indicated that the infraorbital nerve affection was transient in 6 patients and persistent in one patient. After 3 months, 4 patients from group I and 2 patients from group II had 
ejhm.journals.ekb.eg

complete resolution of paresthesia. No significant difference was found in postoperative paresthesia when comparing patients treated with mirror image rapid prototype skull model (group I) and those repaired without (group II). The remaining patient from group II suffered from paresthesia till the end of the observation periods. Persistent paresthesia is likely to be due to compression of the infraorbital nerve in the collapsed canal, or irritation of the nerve by sharp fragments of bone or adhesional bands. Interestingly, the return of infraorbital nerve function continues with an extended observation period and it has been claimed that infraorbital nerve function may continue to improve even after one year following injury ${ }^{(26)}$.

Varying results of persistent impaired function of the infraorbital nerve following different types of treatment have been reported, ranging from $22 \%$ to $50 \%$ persistent hypoaesthesia. It was found that the dynamics and outcome of the functional infraorbital nerve recovery depend on the severity of the injury and the presence of infraorbital canal damage. The function was completely recovered within 3 months after treatment in cases with mild nerve injury. In moderate cases, complete recovery was seen within 6 months and in $34.6 \%$ of the severe cases, within a 12-month period after treatment when infraorbital nerve decompression was performed according to the stated indication ${ }^{(27)}$.

The incidence of hypoaesthesia of the infraorbital nerve is a frequent sequel of fractures of the zygomatic complex occurring in approximately $80 \%$ of such cases and can be reduced if rigid fixation is applied on the infraorbital rim ${ }^{(28)}$. Das et al. ${ }^{(29)}$ evaluated the different neurosensory changes in the infraorbital nerve function following common treatment modalities used in the management of zygomaticomaxillary complex fractures. They found that any form of treatment employed as open reduction and internal fixation (ORIF) or through Gillie's temporal approach or Keen's intraoral approach would provide decompression of the infraorbital nerve, which aid in the recovery of the nerve within a span of 1-6 months.

Intraoperative decompression and rerouting of the infraorbital nerve intraorbitally should be considered especially in cases of zygomatico-orbital and orbital floor fractures involving the infraorbital nerve and the foramen ${ }^{(6,}$ 30). The entrapped infraorbital nerve can have its course altered to traverse along the orbital floor and yet achieve a good result with spontaneous healing, with respect to nerve regeneration and recovery from paresthesia. In contrary to the aforementioned recommendation, Yoon et al. ${ }^{(31)}$ stated that in patients with preoperative hypoesthesia, infraorbital decompression operation was not useful for sensory recovery.

\section{CONCLUSIONS}

Based on the results of the study, it could be concluded that:

- Infraorbital nerve affection is considered as common sequelae after ZMC fracture and nerve recovery in most cases proceeds uneventfully with time.

- Although computer assisted surgery is impressive and has a remarkable role in facilitating the precise contouring and adaptation of the titanium plates/mesh needed for fracture repair, it has no evident advantages over traditional techniques regarding infraorbital nerve recovery.

\section{RECOMMENDATION}

- Longer follow up period is recommended for further and thorough evaluation of infraorbital nerve neuropathy after ZMC fracture and its surgical repair.

\section{REFERENCES}

1. Boswell K (2013): Management of facial fractures. Emerg Med Clin N Am., 31: 539-51.

2. Motamedi M (2003): An assessment of maxillofacial fractures: A 5-year study of 237 patients. J Oral Maxillofac Surg., 61: 61-4.

3. Ferreira P, Marques M, Pinho C et al. (2004): Midfacial fractures in children and adolescents: A review of 492 cases. Br J Oral Maxillofac Surg., 42: 501-5.

4. Czerwinski M, Martin M, Lee C (2005): Quantitative comparison of open reduction and internal fixation versus the Gillies method in the treatment of orbitozygomatic complex fractures. Plast Reconstr Surg., 115: 1848-54.

5. Brasileiro B, Passeri L (2006): Epidemiological analysis of maxillofacial fractures in Brazil: A 5year prospective study. Oral Surg Oral Med Oral Pathol Oral Radiol Endod., 102: 28-34.

6. Kotrashetti S, Kale T, Bhandage $S$ et al. (2015): Infraorbital nerve transpositioning into orbital floor: a modified technique to minimize nerve injury following zygomaticomaxillary complex fractures. J Korean Assoc Oral Maxillofac Surg., 41: 74-7.

7. Renzi G, Carboni A, Perugini M et al. (2004): Posttraumatic trigeminal nerve impairment: a prospective analysis of recovery patterns in a series of 103 consecutive facial fractures. J Oral Maxillofac Surg., 62: 1341-6.

8. Westermark A, Jensen $\mathbf{J}$, Sindet-Pedersen $\mathbf{S}$ (1992): Zygomatic fractures and infraorbital nerve disturbances. Miniplate osteosynthesis vs. other treatment modalities. Oral Surg Oral Diagn., 3: 2730. 
9. Vriens J, Moos K (1995): Morbidity of the infraorbital nerve following orbitozygomatic complex fractures. J Craniomaxillofac Surg., 23: 363-8.

10. Peltomaa J, Rihkanen H (2000): Infraorbital nerve recovery after minimally dislocated facial fractures. Eur Arch Otorhinolaryngol., 257: 44952.

11. Zachariades N, Papavassiliou D, Papademetriou I (1990): The alterations in sensitivity of the infraorbital nerve following fractures of the zygomaticomaxillary complex. J Craniomaxillofac Surg., 18: 315-8.

12. Fogasa W, Ferreira $M$, Dellon A (2004): Infraorbital nerve injury associated with zygoma fractures: Documentation with neurosensory testing. Plast Reconstr Surg., 113: 834-8.

13. Vriens $J$, van der Glas $H$, Bosman $F$ et al. (1998): Information on infraorbital nerve damage from multitesting of sensory function. Int $\mathbf{J}$ Oral Maxillofac Surg., 27: 20-6.

14. Toro C, Robiony M, Costa F (2007): Feasibility of preoperative planning using anatomical facsimile models for mandibular reconstruction. Head Face Med., 3: 5-14.

15. Exadaktylos A, Sclabas G, Smolka K (2005): The value of computed tomographic scanning in the diagnosis and management of orbital fractures associated with head trauma: a prospective, consecutive study at a level I trauma center. J Trauma, 58: 336-41.

16. Bibb R, Eggbeer D, Evans P (2009): Rapid manufacture of custom fitting surgical guides. Rapid Prototyping J., 15: 346-53.

17. Levine J, Patel A, Saadeh $P$ et al. (2012): Computer-aided design and manufacturing in craniomaxillofacial surgery: the new state of the art. J Craniofac Surg., 23: 288-93.

18. Mehra P, Miner J, Innocenzo $\mathrm{R}$ et al. (2011): Use of 3-D Stereolithographic Models in Oral and Maxillofacial Surgery. J Maxillofac Oral Surg., 10: 6-13.

19. Liu $P$, Wong $T$, Fang $J$ et al. (2014): 3D stereolithographic modeling technique for hemimandibular reconstruction, report of a case with innovation technique. Open J Dent Oral Med., 2: 9-13.

20. Randall A, Chang S, Cudejkova M et al. (2013): Computer-guided orbital reconstruction to improve outcomes. JAMA Facial Plast Surg., 15: 113-20.

21. Park S, Choi J, Koh K et al. (2015): Mirror imaged rapid prototype skull model and pre molded synthetic scaffold to achieve optimal orbital cavity reconstruction. J Oral Maxillofac Surg., 73: 1540-53.

22. Cao S, Zheng M, Hua Y et al. (2016): Hematoma changes during clot resolution after experimental intracerebral hemorrhage. Stroke, 47: 1626-31.

23. Somasundaram A, Laxton A, Perrin R (2014): The clinical features of periorbital ecchymosis in a series of trauma patients. Injury, 45: 203-5.

24. Rajati M, Bakhshaee M, Khazaeni K (2013): Periorbital ecchymosis and subconjunctival hemorrhage following ear surgery. ISRN Otolaryngology, 79: 106-8.

25. Sakavicius D, Juodzbalys G, Kubilius R et al. (2008): Investigation of infraorbital nerve injury following zygomaticomaxillary complex fractures. J Oral Rehab., 35: 903-16.

26. Beigi B, Beigi $M$, Niyadurupola $N$ et al. (2017): Infraorbital nerve decompression for infraorbital neuralgia/causalgia following blowout orbital fractures: a case series. Craniomaxillofac Trauma Reconstr., 10: 22-8.

27. Taicher S, Ardekian L, Samet $\mathbf{N}$ et al. (1993): Recovery of the infraorbital nerve after zygomatic complex fractures: a preliminary study of different treatment methods. Int J Oral Maxillofac Surg., 22: $339-41$.

28. Westermark A, Jensen J, Sindet-Pedersen S (1992): Zygomatic fractures and infraorbital nerve disturbances. Miniplate osteosynthesis Vs. other treatment modalities. Oral Surg Oral Diagn., 3: 2730.

29. Das A, Bandopadhyay M, Chattopadhyay A et al. (2015): Clinical evaluation of neurosensory changes in the infraorbital nerve following surgical management of zygomatico-maxillary complex fractures. J Clin Diagn Res., 9: 54-8.

30. Rao A, Jesudas J (2017): An alternative route for entrapped inferior orbital nerve in orbital floor fracture. J Craniomaxillofac Trauma Reconstr., 10: 230-8.

31. Yoon T, Choi Y, Cho J et al. (2016): Primary Infraorbital Foramen Decompression for the Zygomaticomaxillary Complex Fracture: Is It Essential? J Craniofac Surg., 27: 61-3. 